\title{
Editorial for EAIT 2016, Issue 4
}

\author{
Arthur Tatnall ${ }^{1}$
}

Published online: 2 May 2016

(C) Springer Science+Business Media New York 2016

Education and Information Technologies now has a new Editorial Board with some of the previous members as well as some new members. The Editor-in-Chief: Arthur Tatnall (Victoria University, Australia) and the Associate Editors: Tony Jones (University of Melbourne, Australia) and Bill Davey (RMIT University, Australia) have not changed.

Editorial Board members now are: Faten Abdel-Hameed (University of Bahrain), Andreas Breiter (University of Bremen, Germany), Torsten Brinda (Universität Duisburg-Essen, Germany), Joseph Chao (Bowling Green State University, Ohio, USA), TaTao Chuang (Gonzaga University, Washington, USA), Helen Drenoyianni (Aristotle University of Thessaloniki, Greece), David Gibson (Curtin University, Australia), Monique Grandbastien (Université Henri Poincaré Nancy 1, France), Chenglie Hu (Carroll University, Wisconsin, USA), John Impagliazzo (New York, USA), Yaacov Katz (Bar-Ilan University, Israel), Jared Keengwe (University of North Dakota, USA), Maria Kordaki (University of the Aegean, Greece), Timo Lainema (University of Turku, Finland), Ho Cheong Lam (Hong Kong Institute of Education), Chris Leslie (NYU Tandon School of Engineering, USA), Johannes Magenheim (University of Paderborn, Germany), Raymond Morel (Swiss Academy of Engineering Sciences), Jari Multisilta (Tampere University of Technology, Finland), Kevin Parker (Idaho State University, USA), Don Passey (Lancaster University, UK), Sigrid Schubert (University of Siegen, Germany), Nicholas Reynolds (University of Melbourne, Australia), Mikko Ruohonen (University of Tampere, Finland), Eric Sanchez (University of Fribourg, Switzerland), Sindre Røsvik, (Giske commune, Norway and TC3 Chair), Lampros Stergioulas (Brunel University, UK), Joe Turner (Clemson University, USA), Scott Turner (Virginia Tech, USA), Peter Waker (Computer Olympiad, South Africa), Mary Webb (King's College, London, UK) and Joke Voogt (University of Amsterdam and Windesheim University of Applied Sciences, Netherlands).

Arthur Tatnall

Arthur.Tatnall@vu.edu.au

1 Victoria University, PO Box 14428, Melbourne 8001, Australia 
The first article in this issue is: "Adolescents and Cyber Bullying: The Precaution Adoption Process Model' in which John Chapin from Pennsylvania State University, USA documents adolescents' Facebook use and experiences. His study points out that $75 \%$ of middle school Facebook users have experienced cyber bullying. His study applied the Precaution Adoption Process Model to test this with children and adolescents. Results suggest that most adolescents are aware of cyber bullying and acknowledge it as a problem in their school, but were also optimistic in believing they were less likely than peers to be affected by this.

B. Sriram from Sur University College, Sultanate of Oman writes on "Factors Influencing the Internet Resource Users' Satisfaction: An Analytical Study on Omani Undergraduate Learners". The article notes that internet resources are an important knowledge sharing tool in day-to-day business processes and also have a great impact in education, becoming an integral part of the educational system as online resources can help students to acquire knowledge through self-learning. The article reports on an analytical study to find how the use of internet resources impacts on Omani learners' learning processes, and proposes an impact model for this. The results show that factors like easiness, usefulness and knowledge supports have positive impacts on Omani learners' satisfaction.

"Measuring Business Process Learning with Enterprise Resource Planning Systems to Improve the Value of Education" was contributed by Ellen Monk from the University of Delaware, USA and Mark Lycett from Brunel University, UK. The article begins by explaining that an Enterprise Resource Planning (ERP) System is a very large and complex software package that runs every aspect of an organisation. They point out that ERP systems are increasingly being used in higher education as a way to teach business processes. The article reports on a research study that used a critical realist approach to measure business process learning from experiential ERP. The study used a business simulation game to help understanding of business processes and involved students from a US undergraduate program in three separate classes with one using ERP experientially. The results were seen to validate the use of ERP in the classroom.

Educators, government bodies and employers have all acknowledged the need for modern learners to acquire 21 st century skills using ICT to personalise student learning. "Beyond Traditional Literacy: Learning and Transformative Practices using ICT" by Therese Keane and Aaron S. Blicblau from Swinburne University of Technology and William Keane from Emmaus College, Victoria, Australia addresses this concern, pointing out that students need broader skills than the $3 \mathrm{Rs}$ to operate in the 21 st century. These broader skills known as the $4 \mathrm{Cs}$ include: creativity, communication, collaboration and critical thinking. The use of ICT is seen as crucial in developing the 4Cs in conjunction with understanding how learning takes place.

In "Examining Antecedents of Knowledge-Sharing Factors on Research Supervision: An Empirical Study", Arash Khosravi and Mohammad Nazir Ahmad from Universiti Teknologi Malaysia argue that the use of an effective supervision mechanism between a student and supervisor is crucial. Their study aimed to assess the impact of individual, organisational and technical factors on knowledge sharing in relation to research supervision. A specific research model was developed based on systematically analysing and extracting all the knowledge-sharing impact factors 
(individual, organisational and technological) and then choosing the more iterative and adaptable ones. The research results showed that individual factors in the research supervision domain, the ability of students to share knowledge along with technological factors (IT systems) have the greatest impact on knowledge sharing in the supervision process.

Irene-Angelica Chounta and Nikolaos Avouris from the University of Patras, Greece present an article on the integration of a real time evaluation method of collaboration quality in a monitoring application that supports teachers in class orchestration. "Towards the Real-Time Evaluation of Collaborative Activities: Integration of an Automatic Rater of Collaboration Quality in the Classroom from the Teacher's Perspective" describes how this is implemented as an automatic rater of collaboration quality and studied in a real time scenario of use. The article argues that automatic and semiautomatic methods which provide assessments of collaboration quality or detect disorders and anomalies in collaborative activities should be further used to assist class monitoring.

Next is an article by Maria Kordaki (University of the Aegean, Greece), Marina Papastergiou (University of Thessaly, Greece) and Panagiotis Psomos (University of the Aegean, Greece). "Student Perceptions in the Design of a Computer Card Game for Learning Computer Literacy Issues: a Case Study" describes an empirical study designed to investigate the perceptions of entry-level non-computing majors-Physical Education and Sport Science undergraduate students, about basic Computer Literacy issues. The students' prior knowledge was utilised to design and implement an Educational Computer Card Game aimed at helping them overcome their conceptual difficulties and approach the learning issues in a scientifically consistent manner.

"The K-12 Educational Technology Value Chain: Apps for Kids, Tools for Teachers and Levers for Reform" by Glenn Pierce and Paul Cleary (Institute for Security and Public Policy, Northeastern University, Boston, USA notes that historically implementing, maintaining and managing educational technology has been difficult for K-12 educational systems and so opportunities for significant advances in K-12 education have often gone unrealised. A major public policy question is how best to insure educational technology resources can reach all K-12 students in the shortest time and most equitable way possible and their article adopts an educational technology value chain model to assess potential avenues and barriers to implementing educational technology in K-12 systems.

Nina Abdul Razzak, Bahrain Teachers' College, University of Bahrain argues that highly-traditional education systems that offer mainly direct instruction usually result in graduates with a surface approach to learning, rather than a deep one. The article points out that deep-learning is learning that involves critical analysis, the linking of ideas and concepts, creative problem solving, and application. "Strategies for Effective Faculty Involvement in Online Activities Aimed at Promoting Critical Thinking and Deep Learning" argues that this kind of deep learning is what the current national educational reform initiatives in Bahrain are trying to promote. One strategy suggested in the article as a means of promoting critical thinking and deep learning is increasing faculty involvement with students in online contexts.

The next article explores uses of Learning Management Systems (LMS) in teaching Business Mathematics in Hungarian undergraduate training, but from the 
point of view of the instructors. "Using Learning Management Systems in Business and Economics Studies in Hungarian Higher Education" by Judit Nagy from Edutus College, Budapest, Hungary investigates which LMS systems are being used by instructors, to what specific purposes and how intensively. This study showed that, in common with other studies, LMS were commonly used by instructors for text-based communication and for delivering text-based learning materials, but that the proportion of instructors using LMS systems in undergraduate Business Mathematics training is lower than might be expected.

"Pre-Service Teachers' Experiences of ICT in Daily Life and in Educational Contexts and their Proto-Technological Pedagogical Knowledge" points out that many pre-service teachers are members of the net generation and are expected to be familiar with different ICTs, yet several studies have indicated that they are not necessarily able to use them for teaching and learning. Sini Kontkanen, Patrick Dillon, Teemu Valtonen, Sami Renkola and Mikko Vesisenaho (Faculty of Philosophy, University of Eastern Finland) and Pertti Väisänen (Agora Center, University of Jyväskylä, Finland) argue that the notion of teachers' technological pedagogical knowledge is central to this concern. Their reported research addresses coordinated development of technological pedagogical knowledge with students in their university training and early careers.

The final article for this issue: "Using Educational Technology to Develop Early Literacy Skills in Sub-Saharan Africa" is by Philip Abrami, C. Anne Wade and Larysa Lysenko (Concordia University, Montreal, Canada), Jonathon Marsh (Aga Khan Development Network, France) and Anthony Gioko (Aga Khan Academy, Mombasa, Kenya). The reported research explores the impact of interactive, multimedia literacy software (ABRA) on the reading skills of early elementary students in Kenya. The study involved two groups of grade two English teachers and their students: a control group and an experimental group where ABRA was part of their English Language instruction. After the 13-week intervention, significant and substantial gains in reading comprehension were found for ABRA students as measured by GRADE, a standardised test of literacy.

In the last issue I remarked on the 2015 OECD report: "Students, Computers and Learning: Making the Connection" questioning the use of ICT in the classroom and its impact on student performance. We will shortly be having a special issue of EAIT on this topic, guest edited by Chenglie $\mathrm{Hu}$ from Carroll University in Wisconsin, USA. Details of this special issue will soon be on the EAIT website and I encourage all readers to consider submitting an article.

\section{Arthur Tatnall}

Editor-in-Chief 